\title{
Cystic Fibrosis Carrier Screening
}

National Cancer Institute

\section{Source}

National Cancer Institute. Cystic Fibrosis Carrier Screening. NCI Thesaurus. Code C92764.

A genetic test to determine if either parent has the trait of cystic fibrosis carrier. 